\title{
On Metaeconomic Consensus in Global Management
}

\author{
Antanas Buracas ${ }^{1^{*}}$ \\ ${ }^{1}$ Lithuanian University of Educational Sciences, Vilnius, Lithuania \\ *Antanas Buracas, E-mail: antanas@buracas.com
}

\begin{abstract}
The paper review the metaeconomic approaches in global management (MGM) which include social criteria and tasks arranged into consecutive conceptual system with account of changing normative (or minimax) functions and multicriteria approach detailing admitted hierarchies of those preferences. The systemic taxonomy of the MGM and its structurization are reviewed and conceptualized. The ranking of priorities in the multipurpose economic modelling of social preferences presupposes the weighed comparability of criteria functions on the qualitatively different levels-determining the alternatives of optimization, also multicriteria dynamic equilibrium and the preferable managerial strategies. The stochastic network modelling of universal sustainability for country's economic development, disposable resources' allocation a/o characteristics of complex adaptive systems can be recommended as a productive approach to intellectual management practice. The development of MGM would be more effective with more wide integration of multicriteria approaches, also more sophisticated statistical evaluations of intellectual potential in competitive management. The analytical review of the $M G M$ revealed its significance at the stages of formulating the aim hierarchies, or choosing the optimization criteria, the restrictions on preferences and taxonomy of sustainable development.
\end{abstract}

\section{Keywords}

meta-economics, global management, multiple criteria methods

\section{Introduction}

Main attention in the paper is given to global management methods oriented to the ensuring of universal sustainable and competitive economic growth based on intellectual resources and innovative decisions. Metaeconomicsin Global Management (MGM) is a system of abstract regulative principles to be applied in the universal management theory and practice, p. ex., such as the co-measurability criteria in social economy or efficiency of intellectual potential. At the same time, MGM is a criterial system of specified managerial approaches between the dynamics of real economy and its analytical researches within conventional economics. As a system, MGM underlies the formulation of strategic alternatives for sustainable perspective socioeconomic development.

The importance of MGM is especially increasing with new tasks to measure the efficiency of such complicated and innovative processes as impact of shadow economies and intellectual potential, to evaluate the perspective demand of rather individualized products (lasers, nanotech products, most of 
sophisticated science, leisure, health or cosmetic services, etc.). Substantial impulse to new approaches of the MGM was given by international comparisons of the global intellectual development indices. Their priority is rather full totality of determining and surrounding impact factors, statistically determined solutions of official data integration with expert evaluations, weighed co-measurability of qualitative and quantitative determinants of main selected significant factors according to their importance and task function. It is also can be used in subject or institutional ranking.

The framework of World Bank's Knowledge Assessment Methodology, also the reports of WEF and INSEAD on knowledge-based economy were analyzed as an empirical basis for the conclusions (Bilbao-Osorio, 2015, 2014; Dutta et al, 2015, 2014; Inclusive, 2014; Lanvin, 2015, 2014; Porter et al., 2015; Schwab, 2015; etc.). In particular, MGM multiple criteria approaches were applied by teams evaluating the Global Innovation Index, Network Readiness Index, Global Information Technology Index and Global Talent Competitiveness Index (the last one was developed by joint efforts of the World Intellectual Property Organization, Cornell University, and Human Capital Leadership Institute).

As a meaning acceptable in this article, the Meta-Economics (ME) is interpreted as a methodology of economics or as a system of a higher logical order concerning this field of researches (Buracas; laszlo-zsolnai.net) - similar to metalogic, metamathematics or metaethics. The contents of ME and its definitions are very different from the time it was introduced by Karl Menger (1936) in his efforts to economics mathematizationin connection with neowalrasian approach to the laws of return. In more narrow and popular approach, ME was determined also as a study of the (philosophic or moral) foundations of (sustainable) economics; it was prevailing in the publications by many authors (Crosser, 1974; Schumacher, 1973; Allen, 2000; Parkinson, 2016; Genkin, 2002, etc.); or as a field of synergetic motivation (ecologic, ethical) interests outside of economics based on dichotomy: empathy-altruism, etc. (Lynne, 1999, 2003). At the same time as was rationally summarized by Zsolnai (2013), "monetary economy as subject matter, material hedonism as basic value-commitment and positivism as methodology are erroneous meta-economic choices for economics". The sense of applying meta system approach to organizational decisions was successfully discussed by W. J. M. Kickert, J. P. Van Gigch (1979) a. o. Now functioning Meta-economics Research Center (El Centro de Estudios de Metaeconomia, Madrid), also Meta Economics Consulting Group (Canberra \& Newcastle, http://www.metaeconsult.com.au) are entities providing advisory and consultancy services in environmental policy analysis (asset valuation, resource efficiency, climate change mitigation, structural adjustment, etc.) but not developing MGM itself.

The purpose of this presentation is to reveal the essence of the MGM as a constructive methodological system, also variety of contemporary MGM methods which can be used productively when programming the global competitive advantages. The contribution of the paper consists in the conceptualization of such approach, first-of-all the perspectiveness of multiple criteria methods in cases of universal e-sustainable development based on alternative economic management. The main results were presented when reviewing the real cases of multiple objective approach to decision making and 
evaluations concerning intellectual capital (Metaeconomic, 2013), also entrepreneurship development in newly EU countries (Buracas et al., 2015), global talent evaluations in compared countries of Baltics and Serbia (Buracas \& Navickas, 2015), manufacturing enterprise competitiveness (Buracas et al., 2013). As a limitation of the MGM at now, is the fact that its development would be more effective with more wide integration of multicriteria approaches, also contributing of more sophisticated \& multitask statistical evaluations of intellectual potential into competitive management.

\section{Contents of MGM}

MGM is an system of approaches adopting new methods and criteria for interpreting new economic management cases, like quantitative easing concept, effect of creativity (of intellectual capital), global talent competitiveness, negative interest rate, or the efficiency of any social activity outside the traditional economics.

MGM criteria \& principles are starting to become decisively important under the trends of globalization as the engines of sustainable economic competitiveness and social progress, digitized evaluations of innovative actions. So, the activity of institutional innovators started to be analyzed and/or evaluated by international teams as: optimizers - those improving the efficiency of existing operations or reducing their costs; enablers - those developing the innovative technologies and infrastructure; and transformers - creating new offerings and/or new markets (while eliminating resource dependency).

The economic, managerial and factors and determinants characterizing every group of those institutions as well as parameters characterizing innovation quality and intellectual creativity are not identical; also innovation outperformers and achievers can be revealed by their attitudes concerning innovation policy for development (Dutta et al., pp. XVII-XIX). The innovation quality is dependent of intellectual potential or professional competency and creativity plus necessary IT infrastructure, also entrepreneurship advantages, etc. (Lanvin, 2015; Metaeconomics, 2015, pp. 163-183).

As a system, MGM determines: the general and specific managerial principles and economic criteria; the order of their subordination; their distinction from other social sciences, also interconnections with sociology, psychology, demography; gnoseological and normative conceptualization of constructs, etc. The theoretical aspects of MGM specifies the interconnections between economic axiomatic \& system of principles and methods to be applied in its substantiation in practical analysis and decision making, i.e., MGM conceptualizes the main epistemological and ontological approaches in terms of relation between the economic management and its researches. At the same time, MGM arguments the cases when direct managerial solutions are applied with economic evaluations deviated (or restricted) by higher political or other societal governing aims (financing of researches in knowledge fundamentals, strategic developments with account of territorial safety or under militarization, etc.).

The taxonomical structurization of the MGM include:

1) a theoretical paradigm of economic management fixing its main constituents;

2) the system of managerial principles, postulates, procedures and methods, both general and special, 
their subordination, coordination and interpretation;

3) the criteria and principles of the taxonomical arrangement of the economic methodology, the subordination of the management \& marketing procedures, subsystemic conceptualization and optimization;

4) the criteria of construction, comparability and reliability of different management hypotheses and doctrines;

5) criteria and principles of interconnectivity between researches in management and other fields of economic reality.

The taxonomic interpretation of MGM institutionalization can be presented as follows. The social criteria and tasks may be arranged into consecutive conceptual system instituting its different levels and with account of changing normative (or minimax) functions detailing admitted hierarchies of those preferences at various periods of development. The specific problem is variety of functioning concepts imitating or depicting the same real economic system: the methodological task then is to find non-contradicting solution when interpreting the possible intersection of multilevel utility criteria and different hierarchies (of social preferences). Any sustainable socioeconomic development program integrates both: the rank of criteria based on the common values and other rank differentiating these rational criteria according to the national, ethnic, sexual a/o features, depending of prevailing traditions, achieved level of development, geopolitical factors (climate also), cultural a/o behavioral stereotypes. The MGM approaches are especially important when modelling and managing the e-sustainable socioeconomic development, evaluating the global competitiveness and co-leading risk assessment, etc. Such development may not harm nature, must respect the freedom of future generations and must serve the well-being of people (Zsolnai, 2013).

Some regulative principles \& procedures of MGM were revealed after wide generalization of contemporary researches in changes of $20^{\text {th }}$ century economic paradigms. As most actual, such can be listed (first-of-all accenting those of them Metaeconomics Approach, 2012; Buračas, 1985):

1) internal structurization and complexity;

2) nonlinearity \& amplification, i.e., dynamic change of interrelations between different parts of the economic system in the process, also change of systemic interactions with ecologic a/o environments and reinforcement of decisive factors (including development of inventions);

3) multiplicity of values and purposes determining the characteristics and levels of non-material economic activity, and their fluctuating subordination according to changing aims \& tasks;

4) coherence (or systemic integration of diverse elements, relationships, values) at all levels of its structural composition, including normativeness \& innovation trends;

5) ambivalence of simultaneous or contradictory managerial attitudes seeking of most effective solutions within uncertain situations;

6) negentropic (or negative entropy) orientation toward increasing order seeking to achieve effective organizational order and in risk management; 
7) equifinality (predetermined ability to reach a specified final from different initial states and by different ways using dynamic regulative mechanisms \& achievements);

8) emergence \& positive synergy, i.e., interactive integrity \& resulting multiplicative efficiency; etc.

In particular, new MGM approaches to innovations oriented to global competitivity permit to apply them productively as a criteria for: designing and implementing the investments in knowledge a/o productive resources difficult to measure, evaluating their efficiency \& distributing policy for a future. P. ex., renewed comparative assessment of national wealth as including human (education and health) and green resources revealed substantial differences from indicators previously used for its (wealth) evaluations based only on the GDP (in PPP, as value of all final goods and services) or material productive resources of the nations (Inclusive, 2014). The Adjusted Inclusive Wealth Index (AIWI) becomes more competent managerial tool and framework for programmed solutions based on more exact and complex evaluations of aggregated national economic performance, intellectual potential and resulting socioeconomic well-being indicators. So, Western Europe still significantly surpasses Eastern Europe by relative contribution of average human capital ( 70 and $57 \%$ adequately) but part of its natural capital ( $2 \%$ and $15 \%$ adequately); impact of produced capital is evaluated as equal for both sub-regions ( $28 \%$; op. cit., p. 18). Of the three capital asset categories, investment in produced capital provided the lowest rate of return for the majority of 140 countries; besides, existing core accounts reflect on average only $18 \%$ of a country's inclusive wealth (p. 24) (Note 1). As a result, suggestions to revise the present System of National Accounts (SNA) of the U.N. measuring national AIWI in place of GDP, esp. to include the investments into human capital, most productive component (data on present and future demographic trends, education, and wage or income components), into economic policy-making were presented.

As a result of limited technology, manpower, financial \& intellectual resources, regional innovative management have to orient the policy towards their priority distribution to most perspective developments and projects. So, Robert D. Atkinson, Stephen Ezell, authors of GII-2015 (Information Technology and Innovation Foundation) accents different innovation principles which could be acceptable just for global economies as priority: innovation policy should focus on maximizing innovation in all industries; it should support all types and phases of innovation. At the same time, they also invite to support the creation of key innovation inputs focusing on science, technology, entrepreneurship, engineering, and math (STEEM; pp. 89-98).

MGM is substantially based and directly interconnected with modern multiple criterial assessment techniques and their contemporary applications in stochastic, game \& neural network analysis in marketing a/o fields of contemporary management (Metaeconomics, 2015). MGM approach was helpful when building the stochastic model of universal e-sustainability by matching digital technologies for development interests, disposable resources' allocation a/o characteristics of complex adaptive systems applying correctly the sophisticated neuromethods in finance investing, also solving commercialization of new products of biotech or nanotechnologies, etc. The universal e-sustainability project is orienting 
the governments to develop as priority the intellectual renewables and energy-saving techniques, green computer-managed solutions both within household and social activity, adequately transforming the cultural interests and perspective multitask solutions (Metaeconomics, 2015, pp. 37-150). Some of widely applied progressive MGM techniques of intellectual a/o resources evaluation include such as SWOT, PERT (Program Evaluation and Review Technique), PPPB, critical way, neuronal nets (parallel solutions), operational scales of socio-economic measurements based on them a/o, helped to see the interconnected problems and meta-economic aspects more widely and precisely.

The taxonomic ranking of priorities in the multipurpose imitation of economic aspects of social development presupposes the weighed comparability of criteria functions on the qualitatively different levels - on the aspects of determining the alternatives of optimization, multicriteria dynamic equilibrium, and the preferable managerial strategies. Some specific methodic instruments and concepts, esp. including utility functions (UTADIS), multicriteria scoring (Simple Additive Weighting, Multi-group Hierarchical Discrimination, TOPSIS), are widely applied by the WEF, WB Institute, also in financial analytics (Note 2). Some of them are similar to concepts and principles used in many other fields of applied sciences (like minimax, elasticity, multiple criteria and synergy evaluations).

Complicated multicriteria decisions are certainly often based on the preference of a more probable and less risky socioeconomic alternative to a more desirable but less probable (and sometimes more risky one). At the same time, the economic rationalization of the managerial, investment or consumer solutions quite often may lead to socially unacceptable limitations. Many of the methods adopted for the evaluation of intellectual capital and its economic effect are complicated, not reliable within longer period and, by the realistic recognition, require too many efforts. So, MGM approaches facilitates their applicability, and they can be assessed more reliable by applying, p. ex., in Knowledge assessment methodology etc.

The MGM research \& evaluation technique include many intellectual instruments similar to social sciences in general but more based on multicriteria expert evaluations of social factor matrixes, also multistage regressive analysis of surrounding social, psychological a/o processes of economic activity, helping to take into account the impact of shadow economy, effects of sustainable intellectual development, not measurable side impact of financial bubbles etc.

\section{Some Conclusions}

1) The successful application of MGM approaches was revealed in analytical multiple criteria researches on global competitivity and global innovation reports, also publications of author concerning evaluations of multiple objective approach to decision making when assessing and comparing intellectual capital (Metaeconomics, 2013), also entrepreneurship development in newly EU countries (Buracas et al., 2015), global talent evaluations in compared countries of Baltics and Serbia (Buracas \& Navickas, 2015), manufacturing enterprise competitiveness (Buracas et al., 2013). 
2) As some limitations at now within global e-sustainable managerial programming, the development of MGM would be more effective with more wide integration of multicriteria approaches, also more sophisticated statistical evaluations of intellectual potential in competitive management, including expert assessment of shadow economies, financial bubbles and so on.

3) Metaeconomic contents of management is important for formulating the aim hierarchies, or choosing the optimization criteria in organizational activity, the restrictions and taxonomy of socioeconomic preferences in managing innovative solutions.

4) The creation of modern knowledge based economy and enlargement of its competitive advantage by using MGM achievements are the priorities in programming the sustainable economic development process, especially in the transitional economies.

\section{References}

Allen, J. C. et al. (2000). A Metaeconomics Look at Social Capital, Power, and the Decision to Stay in a Rural Community. Working paper. Lincoln, University of Nebraska, USA.

Bilbao-Osorio, B. et al. (Eds.). (2014). The Global Information Technology Report: Rewards and Risks of Big Data.

Dutta, S. et al. (2015). ICTs for Inclusive Growth. WEF-INSEAD.

Buračas, A. (1985). Metatheoretical Conceptualization of Social Preferences. Science of Science, 5, 3-4, 265-286.

Buračas, A. et al. (2015). Complex Assessment of Essential Financial Indicators in Corporate Governance. European Journal of Economics and Management, 2(2), 88-107.

Buračas, A., \& Navickas, V. (2015). Contents of Global Talent Evaluations: Baltics \& Serbia. TEM Journal-Technology, Education, Management, Informatics, 4(2), 187-196.

Buračas, A., Žvirblis, A., \& Ignotas, A. (2013). The Competitive Edge of a Manufacturing Enterprise: Multicriteria Evaluating. TEM Journal-Technology, Education, Management, Informatics, 2(3), 241-246.

Crosser, P. K. (1974). Prolegomena to All Future Metaeconomics Formation and Deformation ofEconomicThought. Saint Louis.

Dutta S. et al. (Eds.) (2015). The Global Innovation Index, Effective Innovation Policies for Development. INSEAD- Johnson Cornell Univ.-WIPO; (2014): The Human Factor in Innovation.

Genkin, В. (2002). Введениевметаэкономикуиоснованияэкономическихнаук (Introduction into Metaeconomics and Foundations of Economic sciences). Moscow, Norma-INFRA.

Inclusive Wealth Report. (2014). Measuring progress toward sustainability: Summary for decision-makers. Delhi: UNU-IHDP.

Kickert, W. J. M., \& Van Gigch, J. P. (1979). A metasystems approach to organizational decisionmaking. Management Science, 12.

Kuznetsov, B. (2012). Метаэкономика: Rроблемыэкономическогобудущегочеловечества 
(Metaeconomics: Problems of Humanity Economic Future).

ИзвестияУральскогогосударственногоэкономическогоуниверситета, 4(42).

Lanvin, B., \& Evans, P. (Eds.). (2016). The Global Talent Competitiveness Index, 2015: Talent Attraction and International Mobility; Growing Talent for Today and Tomorrow. INSEAD, Adecco, HCLI.

Lynne, G. D. (1999). Divided Self Models of the Socioeconomic Person: The Metaeconomics Approach. Journal of Socio-Economics, 3(28).

Lynne, G. D. (2003). Toward a Dual Motive Metaeconomics Theory. The Journal of Socio-Economics, 35.

Menger, K. (1954). The Logic of Laws of Return: A Study in Meta-economics. Economic Activity Analysis.

Metaeconomics Approach \& Intellectual Resources Evaluation. (2012). Multiple objective methods: Integrating into decision making.

Metaeconomics: Stochastics \& Nanotech. (2015). New Approaches to Contemporary Reality, A. Buracas, Omni Connect, Saarbrücken.

Multiple Criteria Evaluation of Entrepreneurship Development in Newly EU Countries. (2012). Ed. \& co-author A. Buracas, Academic Publishing GmbH \& Co.

Parkinson, F. (2016). What is Metaeconomics? Retrieved from http://www.metaeconomics.co.uk/metaeconomics.html

Porter, M. E. et al. (Eds.). (2015). Social Progress Index.

Schumacher, F. (1973). Small is Beautiful: A Study of Economics as Though People Mattered. Blond \& Briggs.

Schwab, K., \& Xavier, Sala-i-Martín. (2015). The Global Competitiveness Report 2015-2016. WEF.

Zsolnai, L. (2013). The Importance of Meta-Economics. In Responsible Economics. E. F. Schumacher and His Legacy for the 21st Century. H. Opdebeeck, P. Lang Academic Publishers, Oxford, UK.

\section{Notes}

Note 1 . On average, human capital contributed $55 \%$ of overall gains in inclusive wealth, while produced capital contributed $32 \%$ and natural capital 13\% (Inclusive.., 2014, p. 28).

Note 2. UTADIS, i.e., criteria aggregation (incl. a set of utility thresholds) with minimizing the classification error rate.

$\mathrm{MgHD}$ is programming procedures used to develop the alternatives classification models (with minimization of the misclassifications). TOPSIS-Technique for Order Preference by Similarity to Ideal Solution. Also ELECTRE-Elimination and Choice Translating Reality Outrank relationship — can be mentioned between them. 